\title{
The protonation of carbenes: structural effects on the $\alpha$-proton acidity of carbocations
}

\author{
J. R. Keeffe and R. A. More O'Ferrall ${ }^{\mathrm{a}}$ \\ ${ }^{a}$ School of Chemistry and Chemical Biology, University College Dublin, Belfield, Dublin \\ 4, Ireland and Department of Chemistry and Biochemistry, San Francisco State \\ University, 1600 Holloway Avenue, San Francisco, California 94132 \\ E-mail:rmof@ucd.ie
}

The paper is dedicated to Professor Nouria Al Awadi on the occasion of her $55^{\text {th }}$ birthday

\begin{abstract}
Ionisation constants $\left(\mathrm{pK}_{\mathrm{a}} \mathrm{s}\right)$ are reported for proton loss from the $\alpha$-carbon of carbocations forming singlet methyl, dimethyl, phenyl, phenylmethyl, diphenyl, methoxy and methoxymethyl carbenes. Equilibrium constants have been evaluated for isomerisation of the carbenes to alkenes or their reaction with water (hydration) to form alcohols based on G3 calculations and estimates of free energies of transfer from gas to solution. Combining equilibrium constants $\mathrm{p} K_{\mathrm{H} 2 \mathrm{O}}$ for hydration $\left(\mathrm{R}_{2} \mathrm{C}:+\mathrm{H}_{2} \mathrm{O}=\mathrm{R}_{2} \mathrm{CHOH}\right)$ with $\mathrm{pK}$ 作 hydrolysis of the carbocations $\left(\mathrm{R}_{2} \mathrm{CH}^{+}+\mathrm{H}_{2} \mathrm{O}=\mathrm{R}_{2} \mathrm{CHOH}\right.$ $+\mathrm{H}^{+}$) provides the desired $\mathrm{p} K_{\mathrm{a}} \mathrm{s}$ as $\mathrm{p} K_{\mathrm{R}}-\mathrm{p} K_{\mathrm{H} 2 \mathrm{O}}$. For the methyl cation an approximate value of $\mathrm{p} K_{\mathrm{R}}$ $=-43$ is extrapolated from a correlation of hydride ion affinities of ethyl, isopropyl and $t$-butyl cations between the gas phase and solution. Based on $\mathrm{p} K_{\mathrm{H} 2 \mathrm{O}}=-70$ for $\mathrm{H}_{2} \mathrm{C}$ : the $\mathrm{p} K_{\mathrm{a}}$ for the methyl cation is 27 . The range of equilibrium constants for different carbenes (50 log units in $\mathrm{p} K_{\mathrm{H} 2 \mathrm{O}}$ ) points to wide variations in stability, in contrast to kinetic measurements which reflect a uniform lack of selectivity. Remarkably, a comparison of substituent effects on $\mathrm{p} K_{\mathrm{H} 2 \mathrm{O}}$ and $\mathrm{p} K_{\mathrm{R}}$ shows that methyl and phenyl substituents stabilise the carbocation and carbene similarly but that methoxy substituents are more stabilizing for the carbene. The latter finding is consistent with calculation of a larger barrier to rotation of a methoxy group in dimethoxy carbene than in the dimethoxymethyl cation and reports that $O$-substituted carbenes react less rapidly with acids than diarylcarbenes. The behaviour is understandable if inductive effects of electronegative atoms complement donation of an electron pair by resonance in the case of carbenes and oppose it for carbocations. Although errors of 2-3 units are likely for individual $\mathrm{pKs}$, these are mitigated by the large span of values considered and cancellations of systematic errors when structurally related values are compared.
\end{abstract}

Keywords: Carbocations, carbenes, $\mathrm{G} 3$ calculations, $\mathrm{p} K_{\mathrm{a}}$ and $\mathrm{p} K_{\mathrm{R}}$, methyl cation 


\section{Introduction}

The stabilities of carbocations ${ }^{1-4}$ and the protonation of carbenes ${ }^{5-8}$ are interrelated topics which have attracted considerable attention over the past ten years. Normally, the stability of a carbocation in aqueous solution is expressed by equilibrium constants $p K_{R}$ or $\mathrm{p} K_{\mathrm{a}}$, where $\mathrm{p} K_{\mathrm{R}}$ refers to the acid-promoted ionization of the alcohol $\left(\mathrm{ROH}+\mathrm{H}^{+}=\mathrm{R}^{+}\right.$

$+\mathrm{H}_{2} \mathrm{O}$ ) and $\mathrm{p} K_{\mathrm{a}}$ to loss of a proton from a carbon adjacent to the centre of positive charge. However, where a carbocation possesses an $\alpha$-hydrogen there is also a $\mathrm{p} K_{\mathrm{a}}$ associated with loss of that proton to form a singlet carbene.

The two equilibria (distinguished as $\mathrm{p} K_{\mathrm{a}}^{\alpha}$ and $\mathrm{p} K_{\mathrm{a}}^{\beta}$ ) are shown below for the $\alpha$ phenethyl carbocation, $\mathbf{1}$, in Scheme 1. In the scheme, the usual double arrows for equilibria are replaced by single arrows to indicate the directions of reactions. Dissociation of a proton from the $\beta$-carbon atom of $\mathbf{1}$ yields styrene $\mathbf{3}$, and from the $\alpha$ carbon atom the isomeric phenylmethylcarbene, 2 . Not surprisingly the $\beta$-hydrogen acidity of this carbocation is high, with $\mathrm{p} K_{\mathrm{a}}=-14.1 .^{9}$ The acidity of the $\alpha$-hydrogen is much lower on account of the instability of the carbene.

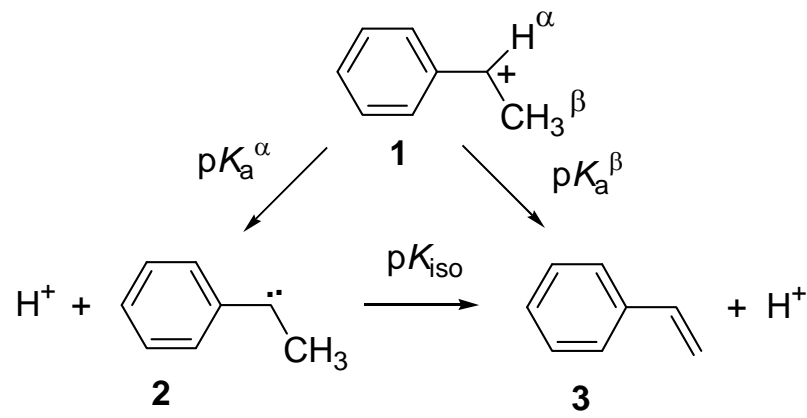

\section{Scheme 1}

Experimental measurements have shown carbenes to be strongly basic. ${ }^{5,7}$ They apply, however, to heterocyclic carbenes ${ }^{5}$ or carbenes bearing heteroatom substituents. ${ }^{7,8}$ This reflects partly the relative accessibility of stabilized carbenes arising from proton loss from the 2-position of methylated imidazolium 4, thiazolium 5 and oxazolium 6 cations, and partly access to $\mathrm{p} K_{\mathrm{a}} \mathrm{s}$ of weakly acidic species afforded by kinetic studies of the deprotonation under conditions that the reverse reaction is subject to diffusion control. ${ }^{5}$ As shown in the chart below, these $\mathrm{p} K_{\mathrm{a}} \mathrm{s}$ fall in the range 17-24. An indirect measurement for the acyclic carbene $(\mathrm{MeO})_{2} \mathrm{C} 7$ in which stabilization is conferred by two heteroatom substituents yields a $\mathrm{p} K_{\mathrm{a}}$ close to the same range. ${ }^{7}$ 


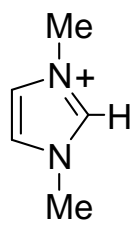

4

$\mathrm{p} K_{\mathrm{a}} \quad 23.0$

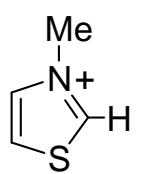

5

19.5

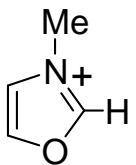

6

16.9<smiles>CO[C+]=[O+]C</smiles>

7

15.5

\section{Chart 1}

These carbenes differ in structure from carbenes such as $\mathrm{CH}_{2}$ and its methyl and phenyl derivatives which lack heteroatom substituents and are commonly encountered as reactive intermediates. The basicity of these species is of practical interest because in methanol or other hydroxylic solvents, protonation remains a likely reaction of the singlet state. ${ }^{6,10}$

In this paper we report estimates of $\mathrm{p} K_{\mathrm{a}} \mathrm{s}$ for protonation of these carbenes based on experimental measurements or G3MP2 calculations ${ }^{11}$ of heats of formation or free energies of reaction to form species of known stability. A feature of the method, which was developed in a previous study of $(\mathrm{MeO})_{2} \mathrm{C}$ :, is the assumption that the solvation energy of the carbene is similar to that of a structurally related saturated species or alkene (e.g. $\mathrm{MeO}_{2} \mathrm{CH}_{2}$ or $\mathrm{MeO}_{2} \mathrm{C}=\mathrm{CH}_{2}$ ). As this assumption seemed to work well (and matched a COSMO calculation) for the potentially polar singlet state of $\mathrm{MeO}_{2} \mathrm{C}$;,we judged it appropriate for alkyl and aryl carbenes, for which lack of a marked solvent dependence of the singlet-triplet energy gap lends qualitative support. Indeed, an attractive procedure for a carbene possessing a $\beta$-hydrogen atom, such as the phenylmethyl-carbene 2 , is to calculate $\Delta \mathrm{G}^{\mathrm{o}}$ for isomerisation of the carbene to an isomeric alkene, in this case styrene. If the solvation energies of alkene and carbene are approximately equal, $\Delta G^{0} / 2.303 R T$ for isomerisation in the gas phase can be combined directly with the aqueous $\mathrm{p} K_{\mathrm{a}}$ for protonation of the alkene to derive the $\mathrm{p} K_{\mathrm{a}}$ of the protonated carbene based on the cycle illustrated in Scheme 1.

In cases where the carbene does not possess an alkene isomer, as for phenyl or methoxy carbenes, or methylene itself, the alkene in Scheme 1 (3) can be replaced by the corresponding alcohol (e.g. $\mathrm{PhCH}(\mathrm{OH}) \mathrm{Me})$. Then, $\mathrm{p} K_{\text {iso }}$ becomes $\mathrm{p} K_{\mathrm{H} 2 \mathrm{O}}$, the equilibrium constant for hydration of the carbene to form the an alcohol $\left(\mathrm{R}_{2} \mathrm{C}:+\mathrm{H}_{2} \mathrm{O} \rightarrow \mathrm{RCHOH}\right)$ and $\mathrm{p} K_{\mathrm{a}}^{\beta}$ becomes $\mathrm{p} K_{\mathrm{R}}$, the equilibrium constant for hydrolysis of the carbocation. Indeed, because of its generality, this modification of Scheme 3 and its implied relationship, $\mathrm{p} K_{\mathrm{a}}^{\alpha}=\mathrm{p} K_{\mathrm{R}}-\mathrm{p} K_{\mathrm{H} 2 \mathrm{O}}$, is the preferred framework for comparing stabilities and basicities of carbenes, as explained more fully below.

A further possibility is to calculate a heat or free energy of hydrogenation of the carbene to an alkane $\left(\mathrm{R}_{2} \mathrm{C}:+\mathrm{H}_{2} \rightarrow \mathrm{R}_{2} \mathrm{CH}_{2}\right)$. This provides a convenient measure of the stability of a carbene and can be linked to the stability of the carbocation through a cycle including the hydride ion affinity of the latter. Hydride ion affinities are more commonly encountered in the gas phase than solution. However, a correlation of hydride ion affinities between the gas phase and solution is considered later in this paper. 


\section{Results}

Experimental measurements of heats of formation in the gas phase have been reported for $\mathrm{H}_{2} \mathrm{C}$ :, ${ }^{12}$ $\mathrm{PhCH}:{ }^{13}$ and $\mathrm{Ph}_{2} \mathrm{C}:{ }^{14} \mathrm{G} 3$ calculations have been carried out for all three species. Good agreement was found for $\mathrm{H}_{2} \mathrm{C}$ :, and, as discussed below, for $\mathrm{Ph}_{2} \mathrm{C}$. . However, the agreement was less good for $\mathrm{PhCH}$ :, for which $\Delta H_{\mathrm{f}}^{\mathrm{o}}(\mathrm{g})$ has been measured for the triplet and can be corrected to $105.8 \pm 2 \mathrm{kcal}$ mol $^{-1}$ for the less stable singlet. ${ }^{13}$ The discrepancy had previously been noted by Nguyen Tho Minh who obtained $113.5 \mathrm{kcal}^{-1}$ from a G3 calculation. ${ }^{15}$ We follow Minh in preferring the calculated value (and for consistency we use our own value of $113.2 \mathrm{kcal} \mathrm{mol}^{-1}$ ). A value of 107 $\mathrm{kcal} \mathrm{mol}^{-1}$, in closer agreement with the measured value, was obtained from a DFT calculation of the energy difference between $\mathrm{H}_{2} \mathrm{C}$ : and $\mathrm{PhCH}$ : based on the isodesmic reaction, $\mathrm{PhCH}$ : $+\mathrm{CH}_{4}=$ $\mathrm{PhCH}_{3}+\mathrm{H}_{2} \mathrm{C}:{ }^{16}$ However, the same DFT method gives a heat of formation for diphenylcarbene which is too small when compared with experimental and G3MP2 values. The discrepancy is understandable because the focus of these calculations was on the structural dependence of singlettriplet energy differences. Inclusion of large carbene structures (such as dinaphthylcarbene) placed a limit on the basis set that could be used and thus on the precision of individual calculated energies.

Experimental and calculated heats of formation of $\mathrm{MeO}_{2} \mathrm{C}$ : have been discussed in a previous paper. ${ }^{7}$ The calculations are now extended to the monomethoxy carbenes, MeOCH: and MeOMeC:, for which no experimental measurements seem to have been reported, as well as to methyl, dimethyl phenyl and diphenyl carbenes. The calculations for dimethoxycarbene have been extended to determine the barrier to rotation about the carbon-oxygen bonds.

Methyl-, dimethyl-, phenylmethyl- and methoxymethyl-carbenes. For these carbenes values of $\Delta H^{0}$ and $\Delta G^{0}$ were calculated for the isomerisation reaction to the isomeric alkene (Table 1). This gave access to a heat of formation of the carbene, by combination with the heat of formation of the alkene. The $\mathrm{p} K_{\mathrm{a}} \mathrm{s}$ for protonation of the carbenes to form carbocations were obtained by combining $\Delta G^{\circ} / 2.303 \mathrm{RT}$ at $25^{\circ} \mathrm{C}$ with $\mathrm{p} K_{\mathrm{a}} \mathrm{s}$ for the protonation of the alkenes to form the same carbocations. The latter values came from combining equilibrium constants for hydration of the alkenes to form alcohols ${ }^{17}$ with values of $\mathrm{p} K_{\mathrm{R}}$ for hydrolysis of the carbocations to form the same alcohols.

The values of $\Delta H^{0}$ and $\Delta G^{0}$ obtained for the isomerisation reactions are listed in Table 1. As expected for this type of isomerisation, $\Delta H^{\circ}$ and $\Delta G^{\circ}$ are very similar. Details of energies calculated for the carbenes and for other structures used in this paper are summarized in Table S1 of the supplementary data. The $\mathrm{p} K_{\mathrm{a}}$ and $\mathrm{p} K_{\mathrm{R}}$ values for the protonated carbenes are shown in Table 2 together with equilibrium constants $\mathrm{p} K_{\mathrm{H} 2 \mathrm{O}}$ for the hydration of the carbene. As noted above, the latter values are obtained as the difference between $\mathrm{p} K_{\mathrm{R}}$ and $\mathrm{p} K_{\mathrm{a}}$ for the carbocations. 
Table 1. Calculated heats and free energies of isomerisation of $\alpha$-methyl carbenes to alkenes

\begin{tabular}{llcc}
\hline & & $\Delta H^{\mathrm{o}}\left(\mathrm{kcal}^{-1}\right)$ & $\Delta G^{\mathrm{o}}\left(\mathrm{kcal}^{-1}\right)$ \\
\hline $\mathrm{CH}_{3} \mathrm{CH} \longrightarrow \mathrm{CH}_{2}=\mathrm{CH}_{2}$ & -75.3 & -74.4 \\
$\left(\mathrm{CH}_{3}\right)_{2} \mathrm{C} \longrightarrow \mathrm{CH}_{3} \mathrm{CH}=\mathrm{CH}_{2}$ & -69.1 & -70.2 \\
$\mathrm{Ph}\left(\mathrm{CH}_{3}\right) \mathrm{C} \longrightarrow \mathrm{PhCH}=\mathrm{CH}_{2}$ & -66.3 & -63.7 \\
$\mathrm{MeO}\left(\mathrm{CH}_{3}\right) \mathrm{C} \longrightarrow \mathrm{MeOCH}=\mathrm{CH}_{2}$ & -37.6 & -37.0 \\
\hline
\end{tabular}

Phenylcarbene. For phenylcarbene no isomerisation to an alkene is possible and values of $\Delta H^{0}$ and $\Delta G^{\mathrm{o}}\left(\mathrm{kcal} \mathrm{mol}^{-1}\right)$ in the gas phase were calculated for the hydration reaction of eq 1 .

$$
\text { PhCH: }+\mathrm{H}_{2} \mathrm{O}=\mathrm{PhCH}_{2} \mathrm{OH} \quad \Delta H^{\mathrm{o}}=-78.1 \quad \Delta G^{\mathrm{o}}=-67.2
$$

By combining $\Delta H^{0}$ with calculated heats of formation for water and benzyl alcohol a heat of formation in good agreement with that evaluated by Minh Tho Nguyen ${ }^{15}$ was obtained as described above. Combining $\Delta H^{0}$ with an estimate of the entropy change for the reaction assuming that $S^{0}$ for $\mathrm{PhCH}$ : could be approximated as that for $\mathrm{PhCH}_{3}$ gave $\Delta G^{0}=-70.2$ in fairly satisfactory agreement with the $\mathrm{G} 3$ value above (-67.2). A minor improvement is achieved by recognizing that the values of $S^{0}$ for a carbene $\mathrm{R}_{2} \mathrm{C}$ : calculated from $\Delta S^{\circ}$ and the entropies of the alkenes in the table above, is often ca. $1.5 \mathrm{cal} \mathrm{K}^{-1} \mathrm{~mol}^{-1}$ less than for the hydrocarbon $\mathrm{R}_{2} \mathrm{CH}_{2}$.

The above values of $\Delta G^{0}$ refer to the gas phase. A value for aqueous solution was derived by assuming that the free energy of transfer from gas to solution for $\mathrm{PhCH}$ : was the same as for $\mathrm{PhCH}_{3}$ corrected for the difference in $\Delta G_{t}$ between $\mathrm{PhCH}_{2} \mathrm{CH}_{3}$ and $\mathrm{PhCH}=\mathrm{CH}_{2}$. This correction amounted to $-0.4 \mathrm{kcal} \mathrm{mol}^{-1}$. Combining $\Delta G_{\mathrm{f}}^{\mathrm{o}}$ (aq) for $\mathrm{PhCH}$ : with values for water and benzyl alcohol from the convenient compilation of Guthrie ${ }^{18}$ allowed calculation of $\Delta G^{\circ}=-70.6$ and the corresponding equilibrium constant $K_{\mathrm{H} 2 \mathrm{O}}$ for hydration of the carbene from the following relationship, in which the values of $\Delta G_{\mathrm{f}}^{\mathrm{o}}$ refer to aqueous solution at $25^{\circ} \mathrm{C}$.

$$
-\mathrm{RT} \ln K_{\mathrm{H} 2 \mathrm{O}}=\Delta G^{\mathrm{o}}(\mathrm{aq})=\Delta G_{\mathrm{f}}^{\mathrm{o}}\left(\mathrm{PhCH}_{2} \mathrm{OH}\right)-\Delta G_{\mathrm{f}}^{\mathrm{o}}(\mathrm{PhCH})-\Delta G_{\mathrm{f}}^{\mathrm{o}}\left(\mathrm{H}_{2} \mathrm{O}\right)
$$

If the equilibrium constant $K_{\mathrm{H} 2 \mathrm{O}}$ is expressed as $\mathrm{p} K_{\mathrm{H} 2 \mathrm{O}}\left(-\log K_{\mathrm{H} 2 \mathrm{O}}\right)$, knowledge of this value $(-51.8$ from eq 2) combined with $\mathrm{p} K_{\mathrm{R}}$ for the benzyl cation allows the desired $\mathrm{p} K_{\mathrm{a}}$ to be deduced from eq 3 , which is based on application of Hess's law to the cycle of Scheme 2. Scheme 2 corresponds to the modification of Scheme 1 referred to in the introduction. 


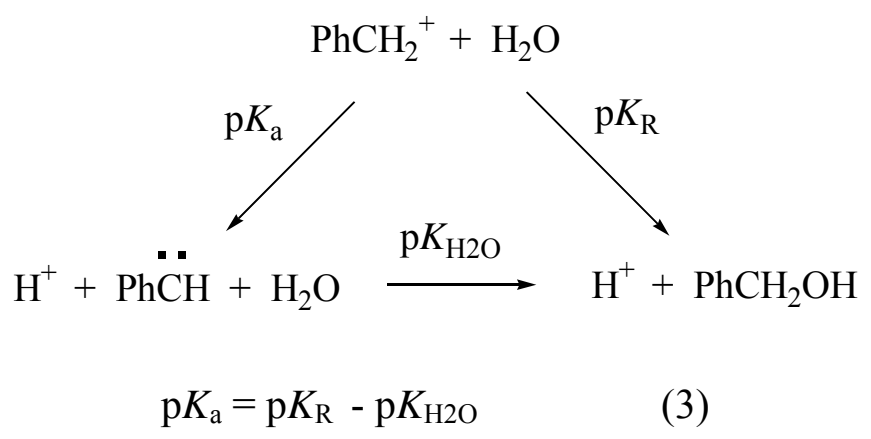

\section{Scheme 2}

Benzyl cation. Amyes, Richard and Novak ${ }^{19}$ showed that $\mathrm{p} K_{\mathrm{R}}$ for this ion must be less than or equal to -20 . A further maximum value can be based on the combination of $\mathrm{p} K_{\mathrm{R}}=-12.4$ for the $p$ methoxybenzyl cation ${ }^{20}$ with methoxy substituent effects, $\Delta \mathrm{p} K=6.8$ and 6.0 respectively, on $\mathrm{p} K_{\mathrm{R}}$ values for the $\alpha$-methyl and $\alpha$-dimethyl benzyl cations. ${ }^{2}$ The difference between these effects will be amplified between the $\alpha$-methyl benzyl and benzyl cation so that $\mathrm{p} K_{\mathrm{R}}$ for the latter should be less than $-12.4-6.8=-19.2$. Wayner et al. estimated $\mathrm{p} K_{\mathrm{R}}$ from a thermodynamic cycle based on the bond dissociation energy of toluene and oxidation potentials of the resulting hydrogen atom and benzyl radicals. Adjusting their value to allow for a revised $\mathrm{p} K_{\mathrm{R}}=-12.5$ for the reference compound, $\mathrm{Ph}_{2} \mathrm{CH}^{+}$, gives $\mathrm{p} K_{\mathrm{R}}=-21.8 .{ }^{21}$ Giving some weight to the estimates of maximum values, we choose -21 as a reasonable approximation to the correct value. It follows from $\mathrm{p} K_{\mathrm{H} 2 \mathrm{O}}=$ -51.8 that $\mathrm{p} K_{\mathrm{a}}=51.8-21=30.8$, which can be rounded to 31 . These values are also included in Table 2 .

Table 2. A comparison of stabilities of singlet carbenes $\left(\mathrm{p} K_{\mathrm{H} 2 \mathrm{O}}\right)$ and carbocations $\left(\mathrm{p} K_{\mathrm{R}}\right)$ in aqueous solution at $25^{\circ}$

\begin{tabular}{lccc}
\hline & $\mathrm{pK}$ & $\mathrm{p} K_{\mathrm{H} 2 \mathrm{O}}$ & $\mathrm{pK}$ \\
\hline $\mathrm{CH}_{3}{ }^{+}$ & -43.0 & -70.0 & 27 \\
$\mathrm{CH}_{3} \mathrm{CH}_{2}{ }^{+}$ & -29.6 & -59.3 & 30 \\
$\mathrm{PhCH}_{2}{ }^{+}$ & -21.0 & -51.8 & 31 \\
$\left(\mathrm{CH}_{3}\right)_{2} \mathrm{CH}^{+}$ & -22.7 & -55.7 & 33 \\
$\mathrm{PhCH}^{+} \mathrm{CH}_{3}$ & -15.7 & -48.3 & 33 \\
$\mathrm{Ph}_{2} \mathrm{CH}^{+}$ & -12.5 & -41.0 & 29 \\
$\mathrm{MeOCH}_{2}{ }^{+}$ & -15.9 & -34.6 & 19 \\
$\mathrm{MeOCH} \mathrm{CH}_{3}$ & -10.3 & -32.9 & 23 \\
$(\mathrm{MeO})_{2} \mathrm{CH}^{+}$ & -5.7 & -18.6 & $13^{\mathrm{a}}$ \\
\hline
\end{tabular}

${ }^{\text {a} P r e v i o u s l y ~ e s t i m a t e d ~ a s ~} 15.5 .^{7}$ 
Diphenylcarbene and benzhydryl cation. $\mathrm{A} p K_{\mathrm{a}}$ for protonation of $\mathrm{Ph}_{2} \mathrm{C}$ : may be estimated from a preliminary measurement of $\Delta H_{\mathrm{f}}^{\mathrm{o}}(\mathrm{g})=114.9 \pm 3.2$ communicated by Kass, ${ }^{14}$ a singlet-triplet separation ${ }^{22} \Delta G_{\mathrm{TS}}=3.3 \mathrm{kcal} \mathrm{mol}^{-1}\left(\Delta H_{\mathrm{TS}}=2.6 \mathrm{kcal} \mathrm{mol}^{-1}\right)$ and $\mathrm{p} K_{\mathrm{R}}=-12.5$ reported by Richard, Amyes and Novak for the benzhydryl cation. ${ }^{20}$ Assigning values of $S^{0}$ and $\Delta G_{\mathrm{t}}$ equal to those for $\mathrm{Ph}_{2} \mathrm{CH}_{2}$ (with a correction of $0.4 \mathrm{kcal} \mathrm{mol}^{-1}$ for $\Delta G_{\mathrm{t}}$ and $+1.5 \mathrm{cal} \mathrm{deg}^{-1}$ for $S^{\mathrm{o}}$ ) gives $\Delta G_{\mathrm{f}}^{\mathrm{o}}(\mathrm{aq})=142.4 \mathrm{kcal} \mathrm{mol}^{-1}$ at $25{ }^{\circ} \mathrm{C}$ for singlet diphenyl carbene.

For the hydration product, benzhydryl alcohol, a value of $\Delta G_{\mathrm{f}}^{\mathrm{o}}(\mathrm{aq})=29.7 \mathrm{kcal} \mathrm{mol}^{-1}$ may be obtained from $\Delta G_{\mathrm{f}}^{\mathrm{o}}(\mathrm{aq})$ for diphenylmethane and an estimate of the increment in $\Delta G_{\mathrm{f}}^{\mathrm{o}}(\mathrm{aq})$ for replacement of a hydrogen by an $\mathrm{OH}$ group, $\Delta G^{\mathrm{OH}}=-37.0 \mathrm{kcal} \mathrm{mol}^{-1}$. The latter quantity is assessed from corresponding values of $\Delta G^{\mathrm{OH}}$ for $\mathrm{CH}_{3} \mathrm{OH}$, and $\mathrm{PhCH}_{2} \mathrm{OH}$ of -34.0 and $-36.0 \mathrm{kcal} \mathrm{mol}^{-1}$ respectively and making allowance for the saturation effect of successively replacing $\mathrm{H}$ by $\mathrm{Ph}$ as described previously. ${ }^{17}$

Then from

$$
\begin{gathered}
-\mathrm{RT} \ln K_{\mathrm{H} 2 \mathrm{O}}=\Delta G_{\mathrm{f}}^{\mathrm{o}}\left(\mathrm{Ph}_{2} \mathrm{CHOH}\right)-\Delta G_{\mathrm{f}}^{\mathrm{o}}\left(\mathrm{Ph}_{2} \mathrm{C}:\right)-\Delta G_{\mathrm{f}}^{\mathrm{o}}\left(\mathrm{H}_{2} \mathrm{O}\right) \\
\text { we obtain } \mathrm{p} K_{\mathrm{H} 2 \mathrm{O}}=-41.0 \mathrm{kcal} \mathrm{mol}^{-1} \\
\text { and } \mathrm{p} K_{\mathrm{a}}=\mathrm{p} K_{\mathrm{R}}-\mathrm{p} K_{\mathrm{H} 2 \mathrm{O}}=-12.5+41.0=28.5 \mathrm{kcal} \mathrm{mol}^{-1}
\end{gathered}
$$

The measured value of $\Delta H_{\mathrm{f}}^{\mathrm{o}}=117.5 \mathrm{kcal} \mathrm{mol}^{-1}$ for singlet $\mathrm{Ph}_{2} \mathrm{C}$ : can be compared with 119.6 from a G3 calculation. Agreement between the two is within the estimated uncertainty of $\pm 3.2 \mathrm{kcal} \mathrm{mol}^{-1}$ for the measured heat, and both values are larger than $112.1 \mathrm{kcal} \mathrm{mol}^{-1}$ calculated by the DFT method referred to in connection with phenylcarbene above. ${ }^{16}$ It should be mentioned that the G3MP2 calculation gave a value for the triplet diphenylcarbene which was $2.6 \mathrm{kcal} \mathrm{mol}^{-1}$ higher than the singlet energy, in contrast to the well-established experimental difference in the opposite direction. The discrepancy was even greater for a GMP2B3 calculation and we speculate that the problem lies with calculation of the geometry of the triplet. In other cases the difference in energy of the singlet and triplet appeared to be reasonable.

A geometry was calculated for the singlet diphenylcarbene at the MP2/6-311G** level and compared with that of the benzhydryl cation. Both structures have virtual $\mathrm{C} 2$ symmetry.The central C-C-C bond angles were found to be $115^{\circ}$ for the carbene and $128^{\circ}$ for the cation. Both carbene and carbocation showed tilting of the phenyl rings, with dihedral angles of $32^{\circ}$ and $21^{\circ}$ between the rings and the $\mathrm{sp}^{2}$ lone pair orbital of the central carbon atom of the carbene and the $\mathrm{C}-\mathrm{H}$ bond to the central carbon of the 
carbocation respectively. Both comparisons of angles are consistent with a greater $\mathrm{p}-\pi$ conjugation for the carbocation than the carbene.

Methoxy- and dimethoxy-carbenes and carbocations. In addition to the calculation in Table 1 for methoxymethyl carbene, heats of formation of methoxy and dimethoxycarbenes, were calculated. These were based on calculations of heats of hydrogenation to form dimethyl ether and dimethoxymethane respectively. Combining the calculated values with experimental heats of formation of the ethers gave heats of formation of 26.2 and $-42.5 \mathrm{kcal} \mathrm{mol}^{-1}$ for $\mathrm{MeOCH}$ : and $(\mathrm{MeO})_{2} \mathrm{C}$ : respectively. The latter value differs significantly from $-38.8 \mathrm{kcal} \mathrm{mol}^{-1}$ obtained from a GMP2 B3 calculation implemented with Gaussian $98 .^{7}$ The heats of formation were converted to free energies in aqueous solution of 33.9 and $-23.2 \mathrm{kcal} \mathrm{mol}^{-1}$ in the manner described for diphenylcarbene above or, in the case of dimethoxycarbene, as described previously. ${ }^{7}$ Combination with experimentally derived values of -70.0 for $\mathrm{MeOCH}_{2} \mathrm{OH}^{18}$ and $-105 \mathrm{kcal} \mathrm{mol}^{-1}$ for $(\mathrm{MeO})_{2} \mathrm{CHOH}^{23}$ gave $\mathrm{p} K_{\mathrm{H} 2 \mathrm{O}}$ values of -34.6 and -18.6 respectively.

As described in the previous paper, the dimethoxycarbene can exist in two planar conformations $\mathrm{W}$ and $\mathrm{Z}$ which are considerably more stable than a $\mathrm{U}$ conformation. ${ }^{7}$ The $\mathrm{W}$ form was calculated to be more stable than the $\mathrm{Z}$ form by $2.3 \mathrm{kcal} \mathrm{mol}^{-1}$ and more stable than the $U$ form by $20.3 \mathrm{kcal} \mathrm{mol}^{-1}$. Of interest is the rotational barrier to interconversion of $\mathrm{W}$ and $\mathrm{Z}$ forms, which provides an indication of the strength of the resonance interaction between the oxygen atoms and the empty $p$-orbital of the central carbon atom. Including zero point energy corrections from scaled $\mathrm{HF} / 6-311+\mathrm{G}^{*}$ frequencies, this was calculated to be $16.9 \mathrm{kcal} \mathrm{mol}^{-1}$ at the $\mathrm{MP} 2 / \mathrm{G} 311+\mathrm{G}^{* *}$ level, with a degree of rotation of $111^{\circ}$, corresponding to $61 \%$ completion, at the point of maximum energy. This is not a complete measure of the loss of resonance because a slight decrease in bond length of the second carbon-oxygen bond suggests a compensating increase in resonance from that oxygen atom (which remains 'in plane').

Protonation of dimethoxy carbene gives the dimethoxymethyl cation, for which the three conformations are $\mathrm{HW}^{+}, \mathrm{HZ}^{+}$and $\mathrm{HU}^{+}$. Now, $\mathrm{HZ}^{+}$is the most stable conformation, being $3.0 \mathrm{kcal} \mathrm{mol}^{-1}$ more stable than $\mathrm{HW}^{+}$, and $9.7 \mathrm{kcal} \mathrm{mol}^{-1}$ more stable than $\mathrm{HU}^{+}$. Rotational interconversion of $\mathrm{HZ}^{+}$and $\mathrm{HW}^{+}$occurs with an activation energy of $14.1 \mathrm{kcal}$ $\mathrm{mol}^{-1}$ with the maximum energy corresponding to a rotational angle of $119^{\circ}$ or $66 \%$ of a complete rotation $\left(\mathrm{HW}^{+} \rightarrow \mathrm{HZ}^{+}\right)$. This is significantly smaller than the barrier of 16.9 $\mathrm{kcal} \mathrm{mol}^{-1}$ for the neutral carbene. In addition, extension of the $\mathrm{C}-\mathrm{O}$ bond of the rotating methoxy group at the point of maximum energy is 0.005 angstroms for the carbocation which is smaller than 0.03 angstroms measured for the carbene. Both factors point to greater resonance stabilization of the carbene than carbocation. Further details of the calculations for different conformations of the carbene and carbocation are given in Tables S2 and S3 of the supplementary data. 
A value of $\mathrm{p} K_{\mathrm{R}}$ for the dimethoxycarbocation has been derived previously. ${ }^{7}$ A value of $\mathrm{p} K_{\mathrm{R}}$ for the methoxyethyl cation was estimated from measurement of a rate constant (2 $\mathrm{x} 10^{10} \mathrm{~s}^{-1}$ ) for reaction of the corresponding 1-ethoxypropyl cation with water by Amyes and Jencks using the azide clock method. ${ }^{24}$ This was combined with an estimate of a rate constant for acid-catalysed formation of the cation from the hemiacetal $\mathrm{MeOCH}(\mathrm{Me}) \mathrm{OH}$ based on 1.75 times the value for the corresponding ethyl acetal. ${ }^{7,25,26}$ The same procedure was followed for the 2-methoxypropyl cation $\left(\mathrm{MeOC}^{+} \mathrm{Me}_{2}\right)$. In this case the rate constant for the diethylacetal of acetone was extrapolated to aqueous solution from measurements in dioxane-water mixtures. ${ }^{27,28} \mathrm{~A}$ value for the methoxymethyl cation was obtained similarly except that reaction of the cation with water was assumed to be controlled by relaxation of the solvent $\left(10^{11} \mathrm{~s}^{-1}\right)^{29}$ and that reaction of the diethyl acetal had been measured directly in water. ${ }^{30}$

Methylene. The value of $\Delta H^{\mathrm{o}} \mathrm{f}(\mathrm{g})$ for the singlet $\mathrm{H}_{2} \mathrm{C}$ : may be taken as $101.8 \mathrm{kcal} \mathrm{mol}^{-1}$. $^{12}$ We then estimate $S^{0}$ as the value of $46.4 \mathrm{cal} \mathrm{deg}^{-1} \mathrm{~mol}^{-1}$ for the triplet $\mathrm{state}^{31}$ less $0.65 \mathrm{cal}$ $\operatorname{deg}^{-1}(R \ln 3)$ and $\Delta G_{\mathrm{t}}=3.6 \mathrm{kcal} \mathrm{mol}^{-1}$ (based on 3.9 for $\mathrm{CH}_{4}$ ) as the transfer free energy from the gas phase to aqueous solution. These values give $\Delta G_{\mathrm{f}}^{\mathrm{o}}(\mathrm{aq})=102.6 \mathrm{kcal} \mathrm{mol}^{-1}$.

Then from

$$
\begin{gathered}
-\mathrm{RT} \ln K_{\mathrm{H} 2 \mathrm{O}}=\Delta G_{\mathrm{f}}^{\mathrm{o}}\left(\mathrm{CH}_{3} \mathrm{OH}\right)-\Delta G_{\mathrm{f}}^{\mathrm{o}}\left(\mathrm{CH}_{2}\right)-\Delta G_{\mathrm{f}}^{\mathrm{o}}\left(\mathrm{H}_{2} \mathrm{O}\right) \\
\mathrm{p} K_{\mathrm{H} 2 \mathrm{O}}=-70
\end{gathered}
$$

Methyl Cation. We can estimate a value of $\mathrm{pK}$ 作 $\mathrm{CH}_{3}{ }^{+}$from a correlation of methyl substituent effects on hydride ion affinities (HIA) from measurements of free energies in the gas phase and solution. For the alkyl cations $\mathrm{CH}_{3} \mathrm{CH}_{2}{ }^{+},\left(\mathrm{CH}_{3}\right)_{2} \mathrm{CH}^{+}$and $\left(\mathrm{CH}_{3}\right)_{3} \mathrm{C}^{+} \mathrm{HIA}$ values in the gas phase can be obtained from measurements of the gas phase basicity of the corresponding alkene ${ }^{32}$ corrected for the difference in free energies of formation for the alkenes and alkanes. ${ }^{18}$ These are listed in Table 3 as $\Delta H I A$, the difference in value from that for the t-butyl cation. Also listed are $\Delta H I A$ for benzyl, vinyl and methoxymethyl cations and their methyl-substituted derivatives. For these ions $\triangle H I A$ is based on measurements or calculations of $\Delta H$ rather than $\Delta G$. As shown in the Table, where both were available there is good agreement between experimental values. and those calculated, and also between values based on $\Delta H$ and $\Delta G$. A more extensive comparison of calculated and experimental HIAs is contained in Table S4 as part of a summary of $\Delta \mathrm{H}$ and $\Delta G$ values for processes considered in this paper. 
In solution, $\triangle$ HIAs were calculated from eq 4 , i.e. the differences in $\mathrm{p} K_{\mathrm{R}}$ for a cation $\left(\mathrm{R}^{+}\right)$and the t-butyl cation converted to free energy at $25{ }^{\circ} \mathrm{C}$ and corrected for the difference in free energies of formation of the respective alcohols and alkanes $\left(\Delta \Delta \mathrm{G}_{\mathrm{f}}^{\mathrm{o}}\right){ }^{18}$ Values of $\mathrm{p} K_{\mathrm{R}}$ and $\Delta \Delta \mathrm{G}_{\mathrm{f}}^{\mathrm{o}}$ are also summarized in Table 3.

$$
\Delta \mathrm{HIA}(\mathrm{aq})=-1.364\left(\mathrm{pK}_{\mathrm{R}}^{\mathrm{R}+}-\mathrm{p} K_{\mathrm{R}}{ }^{\mathrm{But}+}\right)+\Delta \Delta G_{\mathrm{f}}^{\mathrm{o}}(\mathrm{ROH})-\Delta \Delta G_{\mathrm{f}}^{\mathrm{o}}\left(\mathrm{Bu}^{\mathrm{t} O H}\right)
$$

Table 3. Hydride Ion Affinities (HIA) of carbocations in the gas phase and aqueous solution at $25^{\circ}$

\begin{tabular}{llllll}
\hline & $\mathrm{p} K_{\mathrm{R}}$ & $\Delta \Delta G_{\mathrm{f}}^{\mathrm{o}}+44.4^{\mathrm{a}}$ & $\Delta \mathrm{HIA}(\mathrm{aq})$ & $\Delta \mathrm{HIA}(\mathrm{g})$ & $\Delta \mathrm{HIA}(\mathrm{g})^{\mathrm{b}}$ \\
\hline $\mathrm{Me}_{3} \mathrm{C}^{+}$ & -16.4 & 0 & 0 & $0^{\mathrm{c}}$ & $0^{\mathrm{d}}$ \\
$\mathrm{Me}_{2} \mathrm{CH}^{+}$ & -22.7 & 2.0 & 10.6 & 14.5 & 14.7 \\
$\mathrm{MeCH}_{2}^{+}$ & -29.6 & 4.9 & 22.9 & 34.8 & 33.8 \\
$\mathrm{H}_{2} \mathrm{C}=\mathrm{CH}^{+}$ & -39.8 & 0.1 & 32 & 53.2 & \\
$\mathrm{H}_{2} \mathrm{C}^{+} \mathrm{CH}^{+} \mathrm{Me}$ & -32.7 & -0.7 & 21.4 & 25.2 & \\
$\mathrm{PhCH}_{2}{ }^{+}$ & -21.0 & 8.4 & 14.7 & $4.5^{\mathrm{e}}$ & 5.0 \\
$\mathrm{Ph}_{2} \mathrm{CH}_{2}{ }^{+}$ & -12.5 & 7.4 & 2.1 & & -17.9 \\
$\mathrm{PhCH}^{+} \mathrm{Me}$ & -15.7 & 4.9 & 4.0 & -6.85 & -6.2 \\
$\mathrm{PhC}^{+} \mathrm{Me}_{2}$ & -12.5 & 2.8 & -2.1 & -12.5 & -13.0 \\
$\mathrm{MeOCH}_{2}{ }^{+}$ & -15.9 & 0.4 & 1.1 & & 2.1 \\
$\mathrm{MeOCH}{ }^{+} \mathrm{Me}$ & -10.3 & -2.3 & -10.6 & & -15.7 \\
$(\mathrm{MeO}) \mathrm{C}^{+} \mathrm{Me}$ & -5.7 & -2.0 & -17.0 & & -26.7 \\
\hline
\end{tabular}

${ }^{\mathrm{a}} \Delta \Delta G_{\mathrm{f}}^{\mathrm{o}}$ is the difference in free energies of formation alcohol and alkane ( $\mathrm{ROH}$ and $\left.\mathrm{RH}\right)$; $-44.4 \mathrm{kcal} \mathrm{M}^{-1}$ is the corresponding difference between $t$-butyl alcohol and 2,2dimethylpropane (cf eq 4). ${ }^{\mathrm{b}}$ Calculated values are based on enthalpies. Where $\Delta G$ was calculated this differed from $\Delta H$ by less than $1 \mathrm{kcal} .{ }^{\mathrm{c}}$ The gas phase basicity of $\left(\mathrm{CH}_{3}\right)_{2} \mathrm{C}=\mathrm{CH}_{2}$ was taken as $185.4 \mathrm{kcal} \mathrm{M} \mathrm{M}^{-1}$. Free energies of formation of isobutene and 2-methylpropane for the calculation of $\Delta \mathrm{HIA}(\mathrm{g})$ were taken from ref $18 .{ }^{\mathrm{d}}$ The calculated (enthalpic) value of HIA(g) for the $t$-butyl cation was $235 \mathrm{kcal} \mathrm{M}^{-1}$ 


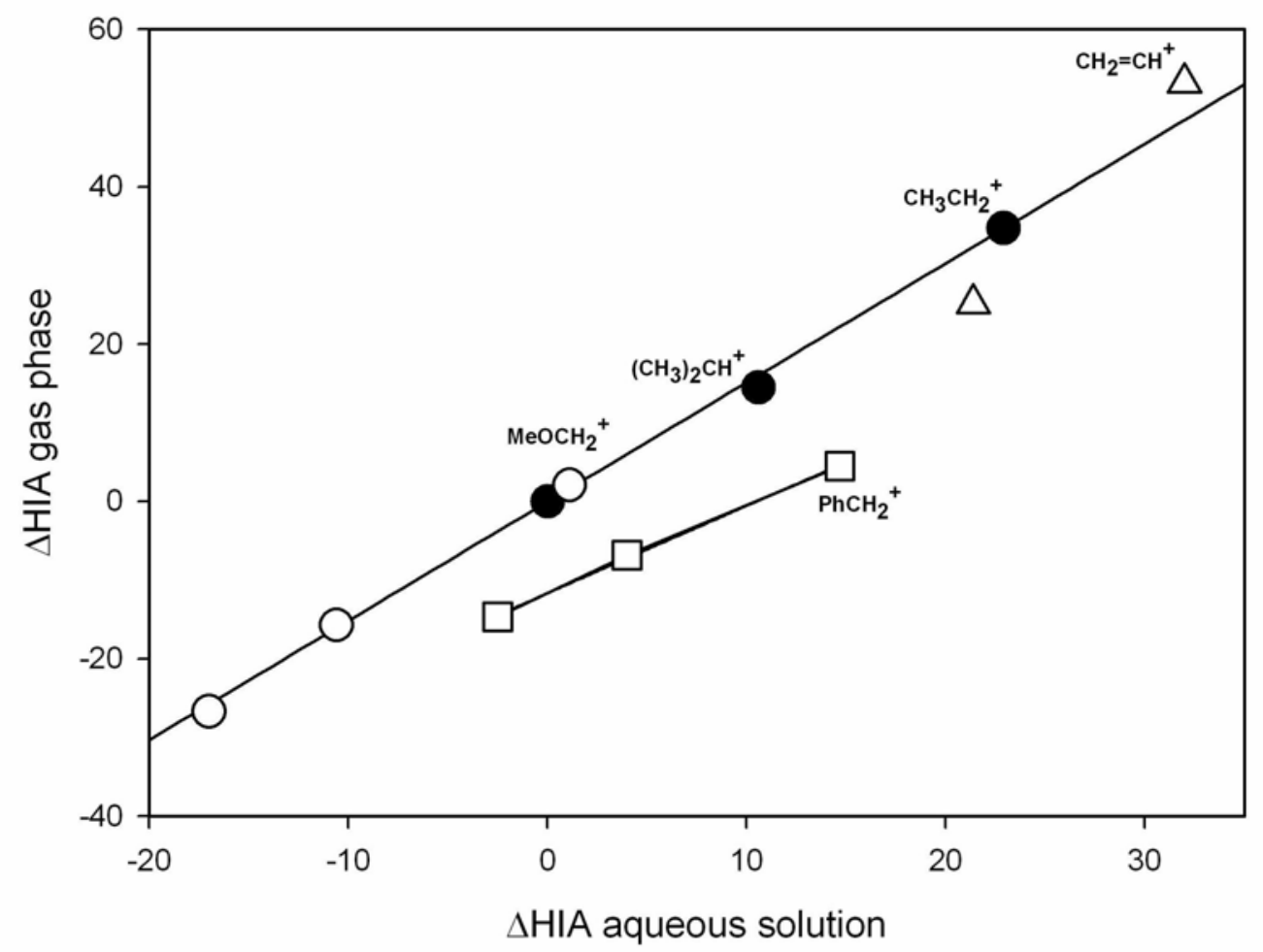

Figure 1. A plot of Hydride Ion affinities for carbocations in the gas phase against corresponding values in aqueous solution at $25^{\circ} \mathrm{C}$. Filled circles, alkyl cations; open circles, methoxyalkyl cations; squares, benzylic cations; triangles, vinyl cations. Upper correlation line $\triangle \mathrm{HIA}(\mathrm{gas})=1.52 \Delta \mathrm{HIA}(\mathrm{aq})-0.27$.

Figure 1 compares effects of one and two methyl substituents on $\Delta H I A s$ for $\mathrm{CH}_{3} \mathrm{CH}_{2}{ }^{+}, \mathrm{PhCH}_{2}{ }^{+}, \mathrm{CH}_{3} \mathrm{OCH}_{2}{ }^{+}$and $\mathrm{CH}_{2}=\mathrm{CH}^{+}$in the gas phase and aqueous solution. The trends in values are consistent with previous studies ${ }^{33-37}$ which have demonstrated that there is no general relationship between gas and solution HIAs for carbocations, but that correlations do exist for related structures such as ring- or $\alpha$-substituted benzyl ${ }^{33}$ or cumyl cations $^{34}$ or bridgehead cycloalkyl carbocations, ${ }^{35}$ and, with somewhat greater scatter, a wider structural range of cations. ${ }^{37}$ From the figure it is clear that methyl substituent effects are also correlated between gas and solution, and that points for benzyl and methoxymethyl cations are well represented by straight lines. In principle, the lines differ in slope and intercept, but points for both alkyl and methoxy cations fit well the common line drawn in the figure.

An approximate value of $\triangle \mathrm{HIA}$ for the methyl cation in aqueous solution can be derived from the data in Fig 1 in two ways. The first is to extrapolate the straight line for the alkoxy and alkyl cations, $\Delta \mathrm{HIA}(\mathrm{g})=1.52 \Delta \mathrm{HIA}(\mathrm{aq})-0.27$, to the gas phase value for the methyl cation and assume that this corresponds with a value for $\mathrm{CH}_{3}{ }^{+}$in solution. 
For $\mathrm{CH}_{3}{ }^{+}$in the gas phase $\Delta \mathrm{HIA}(\mathrm{g})=76.7 \mathrm{kcal} \mathrm{mol}^{-1}$ can be derived from the heat of formation ${ }^{38}$ and entropy of the ion reported by Aboud et al. ${ }^{37}$ This yields $\Delta \mathrm{HIA}(\mathrm{aq})=$ $50.7 \mathrm{kcal} \mathrm{mol}^{-1}$ for $\mathrm{CH}_{3}{ }^{+}$in solution which, after substitution into eq 4 and assigning $\Delta \Delta G_{\mathrm{f}}^{\mathrm{o}}\left(\mathrm{CH}_{3} \mathrm{OH}\right)-\Delta \Delta G_{\mathrm{f}}^{\mathrm{o}}\left(\mathrm{Bu}{ }^{\mathrm{t}} \mathrm{OH}\right)$ as $9.9,{ }^{17}$ gives $\mathrm{p} K_{\mathrm{R}}=-46$.

An indication of the uncertainty of this value is obtained from an alternative extrapolation. Inspection of the points for the alkyl cations in Figure 1 suggests that they are consistent with a mild saturation of substituent effects in the gas phase relative to solution. This might be a reflection of the use of a hydrogen-bridged structure for the ethyl cation in the gas phase and solution. However, by supposing that the relationship between gas and solution $\triangle \mathrm{HIAs}$ can be described by a quadratic equation $\Delta \mathrm{HIA}(\mathrm{g})=$ $1.24 \Delta \mathrm{HIA}(\mathrm{aq})+.0123(\Delta \mathrm{HIA}(\mathrm{aq}))^{2}$ a value of $\Delta \mathrm{HIA}(\mathrm{aq})=43 \mathrm{kcal} \mathrm{mol}^{-1}$ is obtained for $\mathrm{CH}_{3}{ }^{+}$which translates to $\mathrm{p} K_{\mathrm{R}}=-41$. As a compromise between linear and quadratic extrapolations we choose $\mathrm{p} K_{\mathrm{R}}=-43$, which leads to a consistent set of $\mathrm{p} K_{\mathrm{a}}{ }^{\alpha} \mathrm{s}$ for the alkyl cations. It follows that $\mathrm{p} K_{\mathrm{a}}=\mathrm{p} K_{\mathrm{R}}-\mathrm{p} K_{\mathrm{H} 2 \mathrm{O}}=-43+70=27$.

On a historical note, we recall an attempt by Arnett and Hofelich to establish $\mathrm{p} K_{\mathrm{R}}$ values for alkyl cations using heats of reaction of carbocations to bridge a correlation of HIA measurements for alkyl cations in the gas phase with $\mathrm{p} K_{\mathrm{R}}$ measurements for more stable carbocations in aqueous solution. ${ }^{39}$ In an alternative approach, Parker and coworkers demonstrated that HIA measurements in non aqueous solvents could be accessed by combining the $\mathrm{p} K_{\mathrm{a}}$ for ionization of a hydrocarbon with electrode potentials for oxidation of the corresponding carbanion and reduction of the carbocation. ${ }^{40}$

Uncertainties in $\mathbf{p K}$ values. There appears to be no systematic way of estimating the probable error in the value of $\mathrm{p} K_{\mathrm{R}}$ for $\mathrm{CH}_{3}{ }^{+}$but, based on the consistency of the different extrapolations and the effects of methyl, phenyl and methoxy substituents, $\pm 3 \log$ units would seem a reasonable value. Uncertainties in $\mathrm{p} K_{\mathrm{R}}$ for other carbocations are much smaller than this and except for the benzyl cation usually less than $0.5 \log$ units. However, the experimental value of $\Delta H_{\mathrm{f}}^{0}$ for diphenyl carbene was reported ${ }^{14}$ with an error of $\pm 3.2 \mathrm{kcal} \mathrm{mol}^{-1}$, which corresponds to an uncertainty of $2.3 \log$ units in the $\mathrm{p} K_{\mathrm{a}}$ for protonation of this carbene.

For small molecules an error of only $1.25 \mathrm{kcal} \mathrm{mol}^{-1}$ has been claimed for G3 calculations. ${ }^{41}$ This is consistent with the level of agreement between calculated and experimental values for the heat of formation of $\mathrm{H}_{2} \mathrm{C}$ : and for a number of gas phase HIA values for carbocations in Table 3. As already noted, however, our value for the heat of formation for $(\mathrm{MeO})_{2} \mathrm{C}$ : of $-42.5 \mathrm{kcal} \mathrm{mol}^{-1}$, based on a G3MP2 calculation of $\Delta \mathrm{H}^{\circ}$ for hydrogenation to formaldehyde dimethylacetal and the experimental heat of formation for the latter, differs from a previous GMP2B3 calculated heat of formation of $38.8 \mathrm{kcal} \mathrm{mol}^{-1}$. 
In cases where entropies were not calculated, values for the carbenes were approximated by $\mathrm{S}^{\mathrm{o}}$ for the corresponding hydrocarbon with a correction of $1.5 \mathrm{cal} \mathrm{deg}^{-1}$ $\mathrm{mol}^{-1}$ based on comparisons of values for which calculations had been made. Errors from this source are not expected to be large. More problematic are free energies of transfer from gas to solution. However, use of an alkene as a model has the support of a COSMO calculation and again discrepancies are more likely to arise for absolute values than substituent effects.

Despite these uncertainties, a consistent pattern of substituent effects is apparent for the calculated and experimental hydride ion affinities of the carbocations in Table 3. The same is true of heats of hydrogenation of carbenes to the corresponding alkanes, $\Delta \mathrm{H}_{\text {hydrogn }}$ for which values are shown in Table 4 . The heats of hydrogenation may be considered as gas phase counterparts of $\mathrm{p} K_{\mathrm{H} 2 \mathrm{O}}$ for carbenes in aqueous solution. That there are some differences in relative magnitudes of effects of structural changes in the two series stems from significant differences in. $\Delta \mathrm{G}^{\mathrm{o}}$ for substitution of $\mathrm{HO}$ for $\mathrm{H}$ in the hydrocarbon, especially between methoxyalkanes, for which there are strongly stabilizing geminal interactions and methane, toluene and diphenylmethane where these are absent or small. For diphenylmethane and ethyl methyl ether the difference amounts to $10 \mathrm{kcal} \mathrm{mol}^{-1}$ or 7 $\mathrm{p} K$ units.

Table 4. Heats of hydrogenation of singlet carbenes in the gas phase ${ }^{\mathrm{a}}$

\begin{tabular}{lcc}
\hline Carbene & $\Delta H_{\mathrm{f}}^{\mathrm{o}}(\mathrm{g})$ (carbene) & $\Delta H^{\mathrm{o}}$ hydrogn \\
\hline $\mathrm{CH}_{2}{ }^{\mathrm{b}}$ & $101.8 \pm 0.5$ & -119.1 \\
$\mathrm{CH}_{3} \mathrm{CH}$ & 87.9 & -107.9 \\
$\mathrm{FCH}^{\mathrm{c}}$ & $34.2 \pm 3.0$ & -101.0 \\
$\left(\mathrm{CH}_{3}\right)_{2} \mathrm{C}$ & 73.9 & -98.9 \\
$\mathrm{PhCH}$ & 113.2 & -101.1 \\
$\mathrm{ClCH}^{\mathrm{c}}$ & $78.0 \pm 2.0$ & -97.7 \\
$\mathrm{PhCCH}_{3}$ & 101.6 & -94.5 \\
$\mathrm{Ph}_{2} \mathrm{C}^{\mathrm{d}}$ & $117.5 \pm 3.2^{\mathrm{e}}$ & $-84.3^{\mathrm{f}}$ \\
$\mathrm{Cl}_{2} \mathrm{C}^{\mathrm{c}}$ & $55.0 \pm 2.0$ & -77.8 \\
$\mathrm{CF}_{2}{ }^{\mathrm{c}}$ & $-44.0 \pm 2.0$ & -64.1 \\
$\mathrm{MeOCH}$ & 26.2 & -70.2 \\
$\mathrm{MeOCCH}$ & 12.1 & -64.2 \\
$(\mathrm{MeO})_{2} \mathrm{C}$ & $-42.5 \pm 2$ & -40.8 \\
\hline
\end{tabular}

${ }^{a}$ Calculated in this work unless indicated. $\Delta H^{0}$ hydrogn is evaluated directly or from the heats of formation of the carbene and alkane. ${ }^{\mathrm{b}} \operatorname{Ref} 12 .{ }^{\mathrm{c}} \operatorname{Ref} 46 .{ }^{\mathrm{d}} \operatorname{Ref} 14 .{ }^{\mathrm{e}}$ Calculated value 119.6. ${ }^{\mathrm{f}}$ Calculated value -86.4 
The consistency of substituent effects on HIA and $\Delta \mathrm{H}_{\text {hydrogn }}$ is confirmed by satisfactory correlations with gas phase substituent constants, as shown in eqs 5 and 6 . These correlations are based on calculated heats listed in Table S5 of the Supplementary Data, but the values differ insignificantly from those in Tables 3 and 4 .

$$
\begin{array}{ll}
\text { HIA }(\mathrm{G} 3)=-111.6 \sigma_{\mathrm{F}}-178.5 \sigma_{\mathrm{R}^{+}}-34.4 \sigma_{\alpha}-304.1 & \mathrm{r}^{2}=0.945 \\
\Delta \mathrm{H}_{\text {HYDROG }}=-129.3 \sigma_{\mathrm{F}}-175.5 \sigma_{\mathrm{R}^{+}}+14.5 \sigma_{\alpha}-114.7 & \mathrm{r}^{2}=0.985
\end{array}
$$

Computational Methods. All calculated structures were built and optimized at HF/3-21 or HF-6-31G* levels using the MacSpartan Plus software package. ${ }^{43}$ Conformational preferences were established at these or higher levels before completing the geometry optimizations using the G3MP2 method. All structures reported in the paper represent electronic energy minima.

In most cases, calculations were also carried out at the HF/6-311+G** and MP2/6$311+\mathrm{G}^{* *}$ levels with zero point energy corrections made to the MP2 energies using $\mathrm{HF} / 6-31+\mathrm{G}^{* *}$ frequencies scaled by a factor of $0.9135 .{ }^{44}$ This method has been been shown to yield $\Delta \mathrm{H}$ and $\Delta \mathrm{H}^{\neq}$values which differ from those obtained using MP2/6$311+\mathrm{G}^{* *}$ frequencies by an average of $-0.1 \pm 0.5 \mathrm{kcal} \mathrm{mol}^{-1}$ for over 100 enthalpies of reaction and activation. ${ }^{45}$ The GAUSSIAN 03 quantum mechanical package was used for all higher level calculations. ${ }^{11}$ Only the G3 values include thermal corrections.

\section{Discussion}

Despite intensive study over the past fifty years, carbenes remain something of an enigma by comparison with the other principal reactive intermediates of organic chemistry: carbocations, carbanions and radicals. One reason for this is that few reactions leading to the direct formation of carbenes can be studied kinetically. This contrasts, for example, with solvolysis reactions forming carbocations and ionization reactions yielding carbanions. The rates of these reactions are acutely sensitive to the stability of the intermediate formed. Well before unstable carbocations or carbanions could be widely characterised in terms of equilibria their profound influence on rates of reactions had become a hallmark of organic chemistry.

The unstable character of singlet carbenes by contrast has manifested itself in a lack of selectivity between reaction partners in direct reactions of these species. ${ }^{46}$ Commonly, the reactions reach or approach limiting rates set by diffusion of the reactants. Where Hammett. $\rho$ values or other selectivity parameters have been measured they reveal a remarkable insensitivity to variations in structure in contrast to characteristic reactions implicating carbocations or carbanions. ${ }^{47}$ As a consequence adequate measures of the 
influence of structure on the energy of carbenes must be based on measurements of equilibrium constants or energies of reaction rather than rate constants.

Because of experimental difficulties such measurements have relied heavily on computational chemistry and gas phase spectroscopic data. Thus, stabilities of carbenes have been analysed in terms of electron affinities and ionization potentials derived from a combination of calculations and negative ion photoelectron spectroscopy. ${ }^{48}$ We were encouraged to attempt an assessment of stabilities in aqueous solution by the availability on the one hand of $\mathrm{p} K_{\mathrm{a}} \mathrm{s}$ for the protonation of a limited number of 'stable' carbenes (1$4)^{5}$ and on the other of $\mathrm{p} K_{\mathrm{R}}$ values for a much wider structural range of carbocations. ${ }^{1-4}$ The relevance of carbocations to substituent effects on carbenes derives from the common presence of an empty $p$-orbital and susceptibility to strong stabilization by nelectron donating nitrogen and oxygen atoms.

Inspection of Scheme 3, which is a generalized form of Scheme 2, shows that the equilibria corresponding to $\mathrm{p} K_{\mathrm{a}}$ and $\mathrm{p} K_{\mathrm{R}}$ for a carbocation $\left(\mathrm{R}_{2} \mathrm{CH}^{+}\right)$form two arms of a thermodynamic cycle of which the third is the equilibrium for hydration of the carbene $\left(\mathrm{R}_{2} \mathrm{C}\right.$ : ) to the alcohol $\left(\mathrm{R}_{2} \mathrm{CHOH}\right)$, for which the equilibrium constant is denoted $\mathrm{p} K_{\mathrm{H} 2 \mathrm{O}}$. It is then apparent that examining effects of structural changes on $\mathrm{p} K_{\mathrm{R}}$ and $\mathrm{p} K_{\mathrm{H} 2 \mathrm{O}}$ leads to a comparison of substituent effects on the stability of the carbene and carbocation with the alcohol as a common stable product.

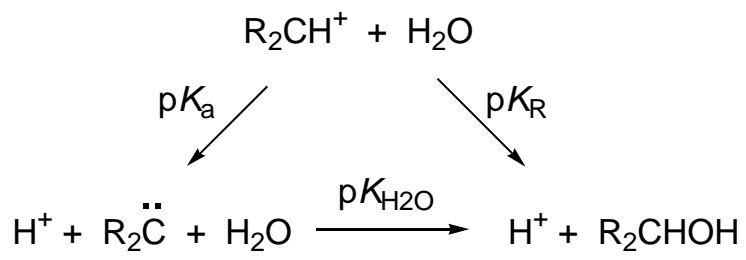

\section{Scheme 3}

In practice, in exploiting this comparison we again rely largely on computed values of $\Delta H$ or $\Delta G$ for reactions of carbenes in the gas phase. As described above these can be adapted to aqueous media by assigning free energies of transfer between gas and solution. Moreover, rather than yielding $\mathrm{p} K_{\mathrm{a}} \mathrm{s}$ directly, the calculations lead to evaluation of $\mathrm{p} K_{\mathrm{H} 2 \mathrm{O}}$, from which $\mathrm{p} K_{\mathrm{a}}$ for protonation of the carbene may be derived if $\mathrm{p} K_{\mathrm{R}}$ for the carbocation is known. This serves well our main interest, namely of comparing values of $\mathrm{p} K_{\mathrm{H} 2 \mathrm{O}}$ and $\mathrm{p} K_{\mathrm{R}}$.

Table 2 lists values of $\mathrm{p} K_{\mathrm{R}}, \mathrm{p} K_{\mathrm{H} 2 \mathrm{O}}$, and $\mathrm{p} K_{\mathrm{a}}$ for methyl, phenyl and methoxy substituted carbocations and carbenes. As discussed above, individual values are subject to significant errors. For the methyl cation $\mathrm{p} K_{\mathrm{R}}$ is derived from extrapolation of a reasonable, but arbitrary, correlation of stabilities of alkyl cations between the gas phase and aqueous solution (Figure 1). For ethyl and isopropyl cations the solution values come 
from kinetic measurements of protonation of alkenes assuming that the alcohol products are not formed by a concerted mechanism. ${ }^{3,49}$

On the other hand the array of carbocation stabilities in Table 2 shows a consistency between more and less well-founded values. For the carbenes themselves values of $\mathrm{p} K_{\mathrm{H} 2 \mathrm{O}}$ are based on a consistent set of calculations, which show an acceptable conformity between calculated and experimental values. Comparisons between $\mathrm{p} K$ values are justified by the large variations, over forty powers of ten, in $\mathrm{p} K_{\mathrm{H} 2 \mathrm{O}}$ and $\mathrm{p} K_{\mathrm{R}}$, as well as the likelihood of cancellation of errors implied by consideration of substituent effects.

Substituent Effects. Of the three substituents, methyl, phenyl and methoxy in Table 2 the behaviour of methyl is the simplest. The methyl group indeed has a significant effect on the stability of both the methyl cation and methylene carbene. As might be expected, the effect on the carbocation is greater, but the difference is remarkably small. A methyl group decreases $\mathrm{p} K_{\mathrm{H} 2 \mathrm{O}}$ for $\mathrm{CH}_{2}$ by $10.7 \log$ units and $\mathrm{p} K_{\mathrm{R}}$ for the methyl cation by 13.4 $\log$ units. This difference may be influenced by uncertainty in $\mathrm{pK}_{\mathrm{R}}$ for $\mathrm{CH}_{3}{ }^{+}$but a second methyl substituent shows similar relative effects. In both cases the effect is consistent with a hyperconjugative interaction between the methyl $\mathrm{C}-\mathrm{H}$ bonds and an empty $p$ orbital of the carbene or carbocation. For the carbene, the preferred geometries calculated for the methyl group in both methyl and dimethyl carbenes are as expected for the occurrence of this interaction. For both the carbene and the carbocation, partial saturation of the substituent effect occurs with the second methyl group exerting a smaller stabilising effect than the first.

As expected the stabilising effect of the phenyl group is greater than that of methyl. Again, the effect of one or two phenyl groups on the carbene is not much less than on the carbocation. A consequence is that, as for methylene and its alkyl derivatives, singlet phenyl, diphenyl and phenyl methyl carbenes are highly basic species. Experimentally, diphenyl carbene has been shown to be sufficiently basic to undergo protonation when generated by photolysis of diphenyldiazomethane in methanol as solvent. ${ }^{10 a}$ Indeed the rate of proton transfer is large enough to compete with intersystem crossing and is controlled by relaxation of the solvent. In principle this is consistent with the relative magnitudes of the $\mathrm{p} K_{\mathrm{a}} \mathrm{s}$ for methanol (16) and that calculated for diphenylcarbene (29) especially if there is a low Marcus intrinsic barrier for the reaction, as is observed for more stable oxygen-substituted carbenes. ${ }^{6,8,50}$

A methoxy group also can be expected to stabilise both a carbocation and a carbene, by interaction of the $p$ orbital of the central carbon atom with a lone pair of electrons on the oxygen atom. Remarkably, the stabilisation of the carbene is substantially greater than that of the cation. Thus a methoxy substituent in methylene decreases $\mathrm{p} K_{\mathrm{H} 2 \mathrm{O}}$ by $35 \log$ units compared with 27 for $\mathrm{p} K_{\mathrm{R}}$, while a second methoxyl further decreases $\mathrm{p} K_{\mathrm{H} 2 \mathrm{O}}$ by 16 units compared with 10 for $\mathrm{p} K_{\mathrm{R}}$. This greater stabilization is reflected in a greater 
resonance interaction between oxygen and the carbon centre as indicated by calculated barriers to rotation of 17 and $14 \mathrm{kcal} \mathrm{mol}^{-1}$ for a methoxy group in dimethoxycarbene and the dimethoxymethyl cation respectively.

The difference of methoxy from methyl and phenyl substituents is indicated graphically in the plot of $\mathrm{p} K_{\mathrm{H} 2 \mathrm{O}}$ against $\mathrm{p} K_{\mathrm{R}}$ in Figure 2 . It can be seen that there is a reasonably linear correlation (with slope 0.92 ) between effects on the stability of the carbocation and carbene for phenyl and methyl substituents, shown as open circles, but that points for methoxy groups (filled circles) deviate strongly. Interestingly, Kirmse has pointed out that relative rates of protonation of oxygen and phenyl substituted carbenes fall in the order $(\mathrm{MeO})_{2} \mathrm{C}:<\mathrm{R}(\mathrm{MeO}) \mathrm{C}:<\mathrm{Ph}(\mathrm{MeO}) \mathrm{C}:<\mathrm{Ph}_{2} \mathrm{C}$ : and thus fail to correlate with the stabilities of the corresponding carbocations. ${ }^{6,50}$ This order is consistent with the estimated order of basicities of the carbenes in Table 2 and especially the larger stabilisation of carbenes by $\mathrm{MeO}$ than $\mathrm{Me}$ or $\mathrm{Ph}$.

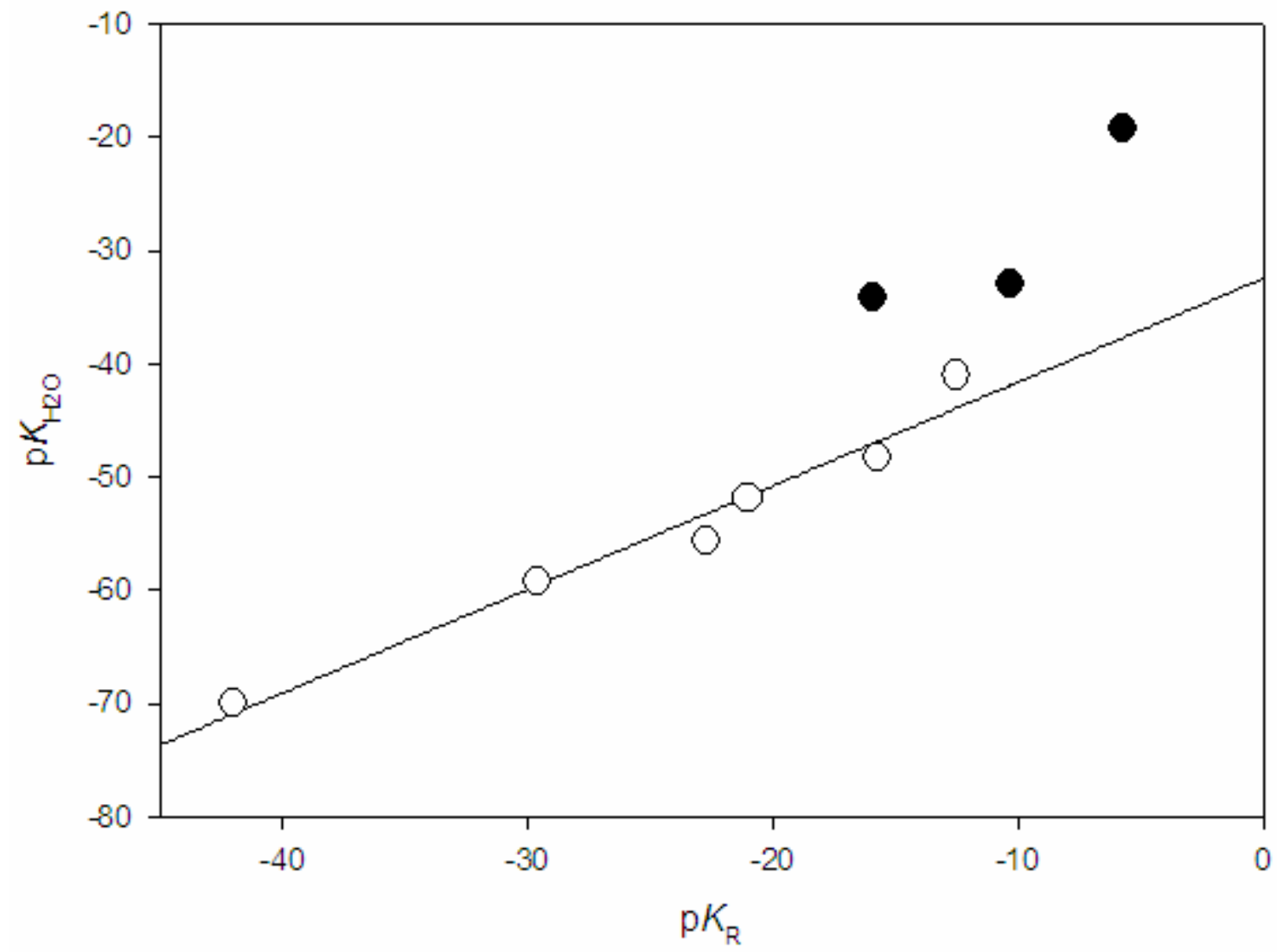

Figure 2. A plot of $\mathrm{p} K_{\mathrm{H} 2 \mathrm{O}}$ for the hydration of carbenes against $\mathrm{p} K_{\mathrm{R}}$ for their conjugate acids in aqueous solution at $25{ }^{\circ} \mathrm{C}$. Open circles, methylene and alkyl or phenyl carbenes; filled circles, methoxy substituted carbenes. Equation of line $\mathrm{p} K_{\mathrm{H} 2 \mathrm{O}}=-32.5+0.92 \mathrm{p} K_{\mathrm{R}}$. 
Heats of hydrogenation. Substituent effects on the stabilities of carbenes are also conveniently examined by comparing their heats of hydrogenation to form alkanes ${ }^{6}$ in the gas phase $\left(\Delta \mathrm{H}_{\text {hydrogn }}\right.$ in eq 7$)$, for which values are listed in Table 4 . Thus the difference in effects of methoxy substitutents from those of alkyl and phenyl groups upon $\mathrm{p} K_{\mathrm{H} 2 \mathrm{O}}$ and $\mathrm{p} K_{\mathrm{R}}$ shown in Figure 2 is also apparent from a plot of heats of hydrogenation of the carbenes against HIA values for the corresponding carbocations in the gas phase in Figure 3.

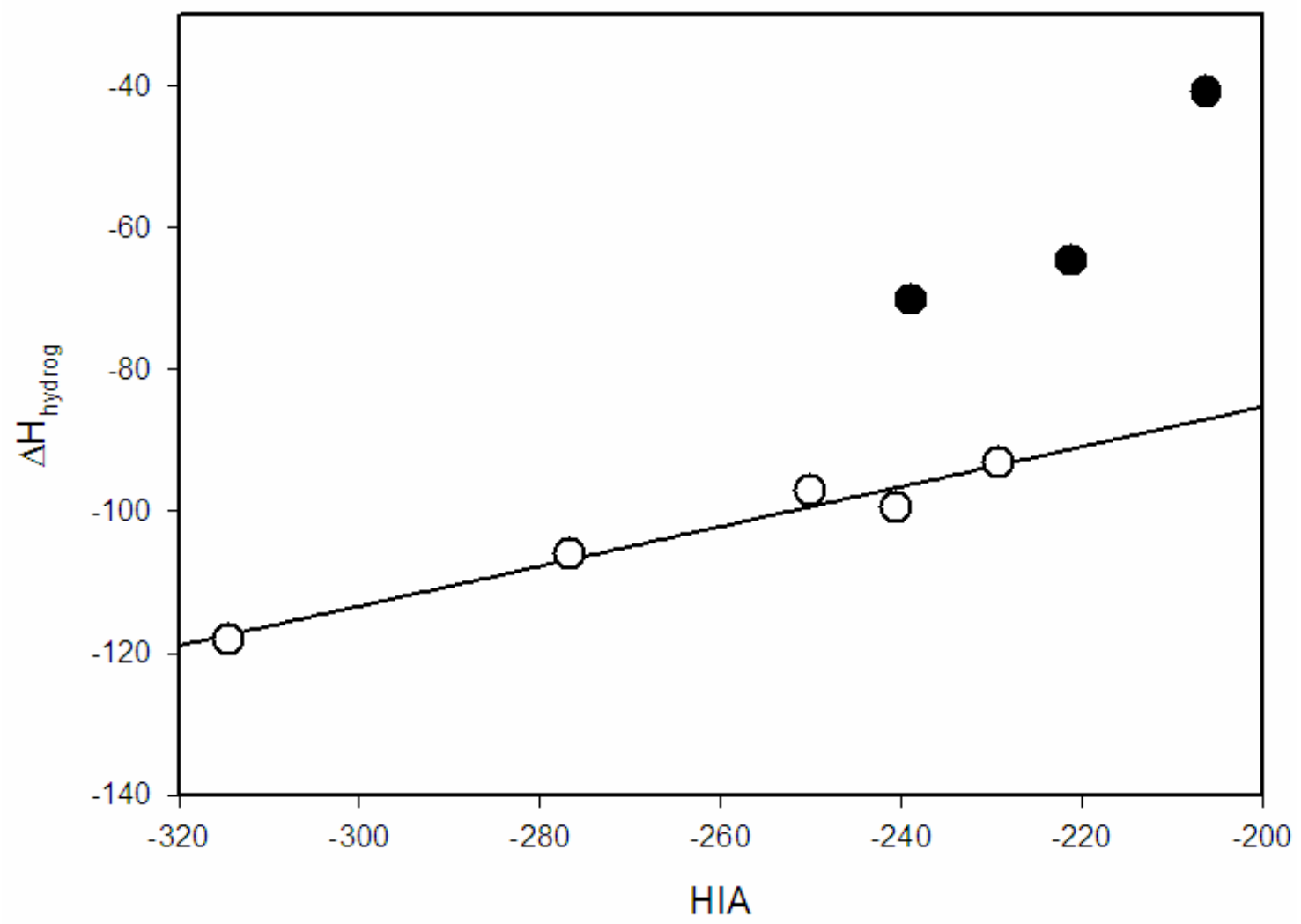

Figure 3. A plot of calculated values of $\Delta \mathrm{H}$ for hydrogenation of carbenes against hydride ion affinities (HIA) in the gas phase. Open circles: $\mathrm{H}_{2} \mathrm{C}$ : $\mathrm{CH}_{3} \mathrm{CH}$ :, $\left(\mathrm{CH}_{3}\right)_{2} \mathrm{C}$ :, $\mathrm{PhCH}$ : $\mathrm{Ph}\left(\mathrm{CH}_{3}\right) \mathrm{C}$ : and $\mathrm{Ph}_{2} \mathrm{C}$ : Filled circles: methoxy substituted carbenes $\mathrm{MeOCH}$; $\mathrm{MeO}\left(\mathrm{CH}_{3}\right) \mathrm{C}$ : and $(\mathrm{MeO})_{2} \mathrm{C}$ : Equation of line: $\Delta \mathrm{H}_{\text {hydrog }}=-22.8+0.30 \mathrm{HIA}$.

The deviations of the methoxy groups persist, despite the effects of alkyl and phenyl substituents on the stability of the carbocations being more than three times as great as in solution.

$$
\mathrm{R}_{1} \mathrm{R}_{2} \mathrm{C}+\mathrm{H}_{2} \stackrel{\Delta \mathrm{H}_{\text {hydrogn }}}{\rightleftharpoons} \mathrm{R}_{1} \mathrm{R}_{2} \mathrm{CH}_{2}
$$


The available data for heats of hydrogenation embrace a wider range of structures and are in most cases more directly related to experimental measurements than comparable values of $\mathrm{p} K_{\mathrm{H} 2 \mathrm{O}}$ for aqueous solution. Thus, by the inclusion of mono and dihalo carbenes in Table $4^{51}$ we are reminded that stabilisation of carbocations provides an incomplete model for conjugative stabilization of the empty $p$-orbital of singlet carbenes. The wellknown stabilities of singlet dichloro and difluoro carbenes, which are comparable with those of phenyl and methyl susbtituted carbenes, are not associated with a corresponding stability for a cation.

. An obvious advantage of the carbene with respect to electronegative substituents such as $\mathrm{F}$ and $\mathrm{Cl}$ is its lack of positive charge. Although for carbocations stabilisation by resonance interaction with a substituent may be thought of as delocalisation of positive charge, it is more properly considered as delocalisation of electrons. In carbenes, as in carbocations, electron delocalisation must lead to delocalisation of charge. However, now the zwitterionic character of the charge, which places a negative charge at the carbenic carbon, favours electronegative substitutents whereas the positive character of the carbocation does not. In other words, the electronegativity and $\pi$-electron donating capacity of substituents are complementary in carbenes but conflicting for carbocations. This difference has been emphasized also in analysing substituent effects upon the reaction of carbenes with alkenes to form cyclopropanes. ${ }^{47}$ In principle, the effect of electronegativity is analogous to back bonding in transition metal complexes in maintaining charge neutrality, as occurs indeed in Fischer carbenes. ${ }^{52}$ A familiar example of a non-polar resonance-stabilised carbene with a formally dipolar electronic structure is carbon monoxide.

These conclusions do not undermine the usefulness of comparing substituent effects on the stabilities of carbenes and carbocations. The comparisons in Tables 2, 3 and 4, and their graphical representations in Figures 2 and 3 emphasise both the common stabilizing effect of electron delocalisation to a $p$ orbital and, as implied in Table 4, the contrasting response of carbene and carbocation to the electronegativity of the substituent. Perhaps the principal import of the comparisons is its emphasis on the sheer magnitude of substituent effects. This magnitude is insufficiently apparent from the characteristic lack of selectivity of carbenes, arising from high reactivity or diffusion control in many of their reactions.

\section{Conclusions}

The main conclusions of the paper may be summarized as follows. (1) A combination of calculated and experimental results leads to estimates of $\mathrm{p} K_{\mathrm{a}} \mathrm{s}$ in the range 13-33 for nine protonated carbenes, including methylene itself and its methyl, phenyl and methoxy 
derivatives. (2) A value $\mathrm{p} K_{\mathrm{R}^{+}}=-43$ for the methyl cation can be extrapolated from a correlation of methyl substitutent effects on the stabilites of carbocations in the gas phase and aqueous solution. (3) An examination of substituent effects on the stabilities of $\mathrm{CH}_{3}{ }^{+}$ and $\mathrm{H}_{2} \mathrm{C}$ : shows that methoxy substituents are more stabilising towards carbenes than carbocations. This last finding, at first surprising, is consistent with effects of other electronegative n-electron-donating atoms such as $\mathrm{F}$ and $\mathrm{Cl}$. It highlights a balance of $\pi$ electron donation and $\sigma$-electron back-donation, which appears to be characteristic of substituents strongly stabilising singlet carbenes.

\section{Supplementary Information}

Supplementary information available includes a summary of enthalpies, free energies and geometric features of species calculated in this work (Table S1); details of conformations of dimethoxycarbene and the dimethoxymethyl cation including energies (Table S2) and geometric features (Table S3); a summary (and comparison) of calculated and experimental energies of reactions, including differences in singlet and triplet energies (Table S4); and calculated values of $\Delta H$ for acid dissociation, HIA and $\Delta H_{\text {hydrog }}$ for eight carbocations (and carbenes) (Table S5)

\section{Acknowledgements}

The authors are indebted to Scott Gronert of Virginia Commonwealth University for helpful discussions and assistance with the computations and to Christopher Hadad of Ohio State University for commenting on the calculation for diphenylcarbene.

\section{References}

1. McClelland R. A., In Reactive Intermediate Chemistry; Moss, R. A.; Platz, M. S.; Jones, M. Eds; Wiley-Interscience: Hoboken, New Jersey, 2004; pp 3-40

2. Richard J. P.; Amyes, T. L.; Lin, S. -S; O’Donoghue, A. C.; Toteva, M. M..; Tsuji, Y.; Williams, K. B. Adv. Phys. Org. Chem. 2000, 35, 67.

3. MacCormac, A. C.; McDonnell, C. M.; More O'Ferrall, R. A.; O’Donoghue, A. C.; Rao, S. N. J. Am. Chem. Soc. 2002, 124, 8575 and references cited.

4. Fujio, M.; Keeffe, J. R.; More O’Ferrall, R. A.; O’Donoghue, A. C. J. Am. Chem. Soc. 2004, 126, 9982. 
5. Amyes, T. L.; Diver, S. T.; Richard, J. P.; Rivas, F. M.; Toth, K. J. Am. Chem. Soc. 2004, 126, 4366.

6. Kirmse, W. In Advances in Carbene Chemistry, Brinker, U. Ed., JAI Press: London, 2000.

7. Guthrie, J. P.; More O’Ferrall, R. A.; O’Donoghue, A. C.; Waghorne, W. E.; Zrinski, I. J. Phys. Org. Chem. 2003, 16, 582.

8. (a) Pezacki J. P. Can. J. Chem. 1999, 77, 1230. (b) Du, D-M.: Fan, H.; Goodman, J. L.; Kesselmayer, M. A.; Krogh-Jesperson, K.; La Villa, J. A.; Moss, R. A.; Shen, S.; Sheridan, R.S. J. Am. Chem. Soc. 1990, 112, 1920.

9. Richard, J. P.; Rothenburg, M. E.; Jencks W. P. J. Am. Chem. Soc. 1984, 106, 1361 $\left(K_{\mathrm{R}}\right.$ reported here has been corrected from $\mathrm{TFE}-\mathrm{H}_{2} \mathrm{O}$ to water). Schubert, W. M.; Keeffe, J. R. J. Am. Chem. Soc. 1972, 94, 559.

10. (a) Peon, J.; Polshakov, D.: Kohler, B. J. Am. Chem. Soc. 2002, 124, 6428. (b) Wang, J.; Burdzinski, G.; Gustafson, T. L.; Platz, M. S. J. Org. Chem. 2006, 71, 6221.

11. GAUSSIAN 03, Revision B.04, Frisch, M. J., et al., Gaussian, Inc., Pittsburgh, PA, 2003.

12. Peterson, G. A.; Al-Laham, A. M. J. Am. Chem. Soc. 1989, 114, 1256.

13. Seburg, R. A.; Hill, B. T.; Squires, R. R. J. Chem. Soc., Perkin Trans 2 1999, 2449. Poutsma J. C.; Nash, J. J.; Paulino, J. A.; Squire, R. R. J. Am. Chem. Soc. 1997, 119, 4686.

14. Kass, S. personal communication

15. Nguyen, T. L.; Kim, G.-S. ; Mebel A. M.; Nguyen, M. T. Chem. Phys. Lettters 2001, 349, 571.

16. Woodcock, L. H.; Moran, D.; Brooks, B. R.; Schleyer, P. v. R.; Schaefer, H. F. III J. Am. Chem. Soc. 2007, 129, 3673.

17. Dey, J.; O’Donoghue, A. C.; More O’Ferrall, R. A. J. Am. Chem. Soc. 2002, 124, 8561.

18. Guthrie, J. P. Can. J. Chem. 1992, 70, 1042.

19. Amyes, T. L.; Richard, J. P.; Novak, M. J. Am. Chem. Soc. 1992, 114, 8032.

20. Toteva, M. M.; Moran, M.; Amyes, T. L.; Richard, J. P. J. Am. Chem. Soc. 2003, 125, 8814.

21. Wayner, D. D. M.; McPhee, D. J.; Griller D., J. Am. Chem. Soc. 1988, 110, 132.

22. Eisenthal, K. B.; Moss, R. A.; Trurro, N. J. Science 1984, 225, 1439.

23. Guthrie, J. P., Can. J. Chem. 1976, 54, 202.

24. Amyes, T. L.; Jencks, W.P. J. Am. Chem. Soc. 1989, 111, 7888.

25. Kresge, A. J.; Weeks, D. P. J. Am. Chem. Soc. 1984, 106, 7140.

26. Ahmed, M.; Bergstrom, R. G.; Cashen, M. J.; Chiang, Y.; Kresge A. J.; McClelland R. A.; Powell, M. F. J. Am. Chem. Soc. 1979, 101, 2669.

27. Kreevoy, M. M., Taft, R. W., Jr. J. Am. Chem. Soc. 1955, 77, 5590. 
28. De Wolfe, R. H.; Jensen, J. L. J. Am. Chem. Soc. 1988, 85, 3264.

29. Toteva, M. M.; Moran, M.; Amyes, T. L.; Richard J. P. J. Am. Chem. Soc. 2003, 125, 8814.

30. Salomaa, P. Suomen Kemis. B 1960, 33, 11.

31. Chase, M. W., Jr., NIST-JANAF Thermochemical Tables, Fourth Edition, J. Phys. Chem. Ref. Data Monograph 9, 1998, 1.

32. Hunter, E. P.; Lias, S. G. J. Phys. Chem. Ref. Data 1998, 27

33. Mishima, M.; Inoue, H.; Fujio, M.; Tsuno, Y. Tetrahedron Lett. 1989, 30, 2101.

34. Richard, J. P.; Jagannadham, V.; Amyes, T. L., Mishima, M.; Tsuno, Y. J. Am. Chem. Soc. 1994, 116, 6706.

35. Abboud, J.-L. M.; Herreros, M.; Notario, R.; Lomas, J. S.; Mareda, J.; Muller, P.; Rossier, J.-C. J. Org. Chem. 1999, 64, 6401.

36. Wolf, J. F.; Abboud, J.-L. M.; Taft, R. W. J. Org. Chem. 1977, 42, 3316.

37. Aboud, J-L., M.; Alkorta, I.; Davalos, J. Z.; Muller, P.; Quintanilla, E. Adv. Phys. Org. Chem. 2002, 37, 57.

38. Ruscic, B.; Litorja, M.; Asher, R. L. J. Phys. Chem. A 1999, 103, 8625.

39. Arnett, E. M.; Hofelich, T. C. J. Am. Chem. Soc. 1983, 105, 2889.

40. Cheng, J.-P.; Handoo, K. L.; Parker, V. D. J. Am. Chem. Soc. 1993, 115, 2655.

41. Baboul, A. G.; Cartiss, L. A.; Redfern, P. C.; Raghavachari, K. J. Chem. Phys. 1999, $110,7650$.

42. Hansch, C.; Leo, A.; Taft, R. W. Chem. Rev.1991, 91, 165.

43. Wavefunction, Inc., 18401 Von Karman Avenue, Suite 370, Irvine CA 92612.

44. Scott, A. P.; Radom, L. J. Phys. Chem. 1996, 100, 16502.

45. (a) Keeffe, J. R.; Gronert, S.; Colvin, M. E.; Tran, N. L. J. Am. Chem. Soc. 2003, 125, 11730. (b) Gronert, S.; Keeffe, J. R., J. Org. Chem. 2006, 71, 5959.

46. Jones, M.; Moss, R. A., In Reactive Intermediate Chemistry; Moss, R. A.; Platz, M. S.; Jones, M. Eds.; Wiley Interscience; Hoboken, New Jersey 2004, 273.

47. Moss, R. A., In Carbene Chemistry, Bertrand, G., Ed., FontisMedia, Lausanne, Switzerland 2002, 57.

48. Sander, W. In Carbene Chemistry, Bertrand, G., Ed., FontisMedia: Lausanne, Switzerland 2002; pp 1-25.

49. Lucchini, V.; Modena, G. J. Am. Chem. Soc. 1990, 112, 6291.

50. Kirmse, W.; Kilian J.; Steenken, S. J. Am. Chem. Soc.1990, 112, 6399.

51. Poutsma, J. C.; Paulino, J. A.; Squires, R. R. J. Phys. Chem. A 1997, 101, 5327.

52. Bernasconi, C. F. Adv. Phys. Org. Chem. 2002, 37, 137. 